\title{
3 Research Square

\section{A cross-sectional, non-interventional study of the correlation between insight and adherence in schizophrenia in Nepal}

Imogen Henrietta Stokes ( $\square$ ixs690@student.bham.ac.uk)

University of Birmingham College of Medical and Dental Sciences https://orcid.org/0000-0001-57372620

Uddhav Lama

Manipal College of Medical Sciences

Jai Bahadar Khattri

Manipal College of Medical Sciences

Research article

Keywords: Schizophrenia; insight; adherence; Nepal

Posted Date: September 17th, 2019

DOI: https://doi.org/10.21203/rs.2.14530/v1

License: (c) (i) This work is licensed under a Creative Commons Attribution 4.0 International License. Read Full License

Version of Record: A version of this preprint was published at Asian Journal of Psychiatry on February 1st, 2020. See the published version at https://doi.org/10.1016/j.ajp.2019.101922. 


\section{Abstract}

Background: There is a significant lack of research in the Nepalese study population on adherence in patients with schizophrenia. This cross-sectional, non-interventional study aims to re-examine the recognised correlation between insight and adherence in this population, whilst exploring the association between patient demographics and adherence to help bring understanding to how familial and environmental factors may impact adherence.

Methods: Patients were recruited upon attendance to outpatient's appointments and admission to the psychiatry department of Manipal Teaching Hospital. A self-report questionnaire was used to collect data on patient demographics, including age, ethnicity, religion, employment status, current living arrangements and education level; the Birchwood Insight Scale (BIS); and the Drug Attitude Inventory (DAl-10) score. Descriptive statistics on the demographics, BIS and DAl-10 were collated using SPSS. An analysis of variance of DAI-10 scores according to participant demographics was performed using a oneway ANOVA analysis. Correlation between the BIS and BIS subscales and the DAI-10 was tested using Pearson's 2-tailed analysis at 0.01 significance level.

Results: 19 participants consented to participate in this study with $100 \%$ data obtained. $57.9 \%$ unemployed, $63.2 \%$ living with parents and $47.4 \%$ had only a basic education. $36.8 \%$ of participants had poor insight; $84.2 \%$ of participants had poor insight into their symptoms; $78.9 \%$ of participants had poor insight into their illness and $36.8 \%$ had poor insight into their need for treatment. $52.7 \%$ of participants were poor adherers. No significant differences in DAl-10 scores were found between demographic groups. A positive correlation was found between the total BIS score and DAI-10 score (Pearson correlation coefficient of $0.585 ; \mathrm{P}$ value $=0.009$ ). Furthermore, the awareness of need for treatment subscale score and the DAl-10 score found a correlation coefficient of 0.609 ( $P$ value $=0.006)$.

Conclusions: In conclusion, this study found prevalent non-adherence to medication and demonstrated that insight correlates with adherence. Although study findings did not suggest that patient demographics were associated with non-adherence, it is important to consider the possibility that these high rates of non-adherence have other contributing factors; overcoming rural health inequality, cultural beliefs regarding psychiatric illness and unaffordability remain the great challenges for the Nepalese population.

\section{Background}

Schizophrenia is psychiatric condition that cause hallucinations, delusions, thought disorder and paranoia; thought to affect about 3 in 1000 adults globally [1]. Schizophrenia is a treated using a combination of cognitive behavioural therapy and anti-psychotic medication, however non-adherence to treatment can make the optimal delivery of these treatments challenging and is recognised as the greatest barrier in the delivery of treatment for this patient population [2,3]. A cross-sectional analysis of 50 patients with schizophrenia performed by Chaudhari et al. in 2017 , showed that $52 \%$ of patients in the 
study were low adherers [4]. In a 2019 study of schizophrenia and bipolar disorder patients, Lee et al. demonstrated rates of non-adherence at 26.4\% 4-weeks post discharge and 37.7\% 24-weeks post hospital discharge [5]. Non-adherence to treatment in patients with schizophrenia is a risk factor for relapse, hospitalisation and suicide and it is thought that poor insight may be the leading cause for nonadherence [6]. A multicentre study by Tessier et al. demonstrated that medication adherence was directly predicted by insight [7]. Bitter et al. presented a study concluding a strong association between insight and compliance, adding further evidence to this hypothesis [8].

Non-compliance to medication is a huge challenge facing Nepalese healthcare, especially when treating psychiatric illness. Non-compliance in the Nepalese population has many contributing factors, including beliefs regarding psychiatric illness, migration, lack of access to nearby treatment, forgetting doctor's appointments, use of faith healers, social stigma, substance misuse, insight, unaffordability and more [9, 10]. A study by Dhungana et al. found that out of 80 cases of non-compliant patients with schizophrenia, $72.5 \%$ had lack of access to nearby treatment [9]. In a study by Ghimire, unaffordability was found to be a factor in $68 \%$ of cases of poor compliance, whereas poor insight was only found to be a factor in $2 \%$ of cases [10].

The rationale for the study is to investigate adherence in patients with schizophrenia in a Nepalese study population where there is currently a significant lack of research. This study hopes to further test the hypothesis that there is a positive correlation between insight and adherence. This study will explore how differing variants of insight in schizophrenia patients may affect adherence. Furthermore, this study will endeavour to explore the association between patient demographics and adherence to help bring understanding to how familial, socio-cultural and environmental factors may impact on adherence.

\section{Methods}

\section{Study Overview}

This is a cross-sectional, non-interventional study. Patients were recruited upon attendance to outpatient's appointments and admission to the psychiatry department of Manipal Teaching Hospital. Recruitment and participation in the study was completed between $10^{\text {th }}$ May 2019 and $10^{\text {th }}$ June 2019. Self-reported data collected included patient demographics, including age, ethnicity, religion, employment status, current living arrangements and education level; the Birchwood Insight Scale (BIS) [11]; and the Drug Attitude Inventory (DAl-10) score [12,13]. The DAl-10 was chosen for its simplicity and good psychometric properties; it is considered just as valid in the measurement of insight in schizophrenia as the DAl-30 [14]. This data was collected to explore the correlation between insight and adherence in schizophrenia; demographic data will be used for a variance analysis to observe for the effect of demographics on adherence. Potential confounders of adherence in this population include consulting a faith healer, complexity of drug regime, side effects, duration of illness and drug and alcohol misuse [9, 10]. 


\section{Inclusion and Exclusion Criteria}

This study recruited patients upon attendance to outpatient appointments or admission to the psychiatric department at Manipal Teaching Hospital in Pokhara, Nepal. Inclusion criteria for the study were a diagnosis of schizophrenia in accordance to ICD-10 disease classification; aged 18 years or over and written consent to the study. Exclusion criteria were acute psychosis or patients with any cognitive deficits which would interfere with their ability to comprehend the questionnaire.

\section{Measures}

Insight was assessed by the BirchwoodInsight Scale (BIS); this measure can explore a participant's awareness of illness, awareness of need for treatment and understanding of symptoms as pathological [11]. BIS is an 8-item self-report scale; the total score from these 8 items can be used to determine the level of insight; 12 indicating full insight, 9 indicating good insight and 0 indicating no insight [11]. BIS subsequently offers a subscale analysis, this can be used to determine awareness of symptoms, awareness of illness and awareness of need for treatment [11].

Adherence was assessed using the Drug Attitude Inventory (DAl-10); this adherence scale was first developed by Hogan et al. in 1983 and has since been condensed by a stepwise discriminant analysis by Awad et al. in 1993 to form a 10-question adherence scale [12,13]. This self-report questionnaire asks the participant about the perceived effects of anti-psychotic drugs. If the patient answers in accordance with how an adherent patient would answer, they receive +1 point for the question. If the patient answers in accordance with how a non-adherent patient would answer, they receive -1 point for the question. Subsequently, the total score for the questionnaire directly correlates to a patient's drug attitude, 0 being a very poor attitude and 10 being the best possible drug attitude $[12,13]$.

\section{Data Collection}

A structured self-report questionnaire was used to collect the data; each questionnaire composed of three sections (section 1: demographics; section 2: Birchwood Insight Scale and section 3: DAI-10) [11-13]. The questionnaire was designed in English and translated to Nepali by the staff of Manipal Teaching Hospital Library. Data was collected by Imogen Stokes (British Medical Student) and Dr Uddhav Lama (First Year Resident Psychiatrist at Manipal Teaching Hospital) between $10^{\text {th }}$ May 2019 and $10^{\text {th }}$ June 2019. Patients were enrolled consecutively into the study. Data was collected and anonymised using a participant number to ensure confidentiality; data was collated in Microsoft Excel using the anonymised participant number.

For illiterate participants, the questionnaire could be read to them by Dr Uddhav Lama, he did not explain or expand upon the questions in any way, but simply repeated the questions if the participants needed; 
this method reduced opportunity for observer bias. All patients eligible for the study that presented at Manipal Teaching Hospital were invited to participate, as to remove selection bias from the study.

Study size was determined by the time scale available to perform the study. Imogen Stokes (British Medical Student) was placed at Manipal Teaching Hospital between the $6^{\text {th }}$ May 2019 and $10^{\text {th }}$ June 2019 , one week was used for preparation and translation of resources and data collection began on the $10^{\text {th }}$ May 2019.

\section{Data Processing and Analysis}

Data was collated in Microsoft excel and subsequently analysed using SPSS version 24 . Descriptive statistics of the demographics, BIS and DAI-10 were collated using SPSS. An analysis of variance of DAI-10 scores according to participant demographics was performed using a one-way ANOVA analysis. Correlation between the BIS and BIS subscales and the DAI-10 was tested using Pearson's 2-tailed analysis at 0.01 significance level.

\section{Ethical Consideration}

Ethical approval was obtained from the Institutional Ethical Review Committee. In line with the Extracts of Nepal Health Research Council (NHRC) Regulations 2002, the research project was responsive to the health needs and priorities of Nepal and was sensitive to the existing cultural and social values [15]. An informed written consent was obtained from the participants. Confidentiality was maintained by removing patient identifiable information.

\section{Results}

\section{Sample}

19 patients were considered for the study, examined for eligibility and subsequently invited to participate in the study. 19 participants were consented to participate in this study with $100 \%$ data obtained on demographics, BIS and DAI-10.

$52.6 \%$ of participants were aged between $21-30$ years old; $52.6 \%$ were male; $31.6 \%$ Bahun ethnic group and $26.3 \%$ Chhetri ethnic group; $63.2 \%$ Hindu and $36.8 \%$ Buddhist; $57.9 \%$ unemployed; $63.2 \%$ living with parents; and $47.4 \%$ had basic education and $47.4 \%$ had a higher secondary education (Table 1 ).

\section{Birchwood Insight Scale (BIS)}

Across the 19 participants in the study, there was a mean BIS score of 8.79 (SD 3.95). 36.8\% of participants had full insight (BIS score $\geq 12$ ); $26.3 \%$ of participants had good insight (BIS score $\geq 9$ ); 
$36.8 \%$ of participants had poor insight (BIS score $\geq 1$ ) and $0.0 \%$ of participants had no insight (BIS score of 0 ) (Table 2).

Upon analysis of the awareness of symptoms subscale, it was found that the mean score across the 19 participants was 2.32 (SD 0.75). $15.7 \%$ of participants had good insight into their symptoms and $84.2 \%$ of participants had poor insight into their symptoms. Upon analysis of the awareness of illness subscale, it was found that the mean score across the 19 participants was 1.63 (SD 1.46). $21.1 \%$ of participants had good insight into their illness and $78.9 \%$ of participants had poor insight into their illness. Upon analysis of the awareness of need for treatment subscale, it was found that the mean score across the 19 participants was 2.42 (SD 1.74). 63.2\% of participants had good insight into their need for treatment and $36.8 \%$ had poor insight into their need for treatment (Table 2).

\section{Drug Attitude Inventory (DAI-10)}

Across the 19 participants in the study, there was a mean DAI-10 score of 1.05 (SD 3.85). $47.4 \%$ of participants had a positive score, indicating a positive drug attitude; $21.1 \%$ of participants had a score equal to zero, indicating a poor drug attitude; $31.6 \%$ of participants had a negative score, indicating a negative drug attitude (Table 2).

\section{Demographics and Adherence}

Results of the one-way ANOVA analysing for variance in DAI-10 scores according to participant demographics found no significant differences in DAI-10 scores between demographic groups (Table 3).

\section{Insight and Adherence}

Pearson 2-tailed analysis for correlation between the 19 participants' scores in the BIS and the DAI-10 found a Pearson correlation coefficient of 0.585 ( $P$ value $=0.009)$, indicating statistically significant positive correlation between the BIS scores and DAI-10 scores of the 19 participants (Table 4).

The awareness of symptoms subscale scores and DAl-10 scores found a correlation coefficient of 0.032 ( $P$ value $=0.895)$, indicating non-significant positive correlation. Similarly, awareness of illness subscale scores and DAI-10 scores found a correlation coefficient of 0.112 (P value $=0.647$ ), indicating nonsignificant positive correlation. However, the awareness of need for treatment subscale scores and the DAI-10 scores found a correlation coefficient of 0.609 ( $P$ value $=0.006)$, indicating statistically significant positive correlation (Table 4).

\section{Discussion}


This cross-sectional, non-interventional study of patients with schizophrenia at Manipal Teaching Hospital in Nepal had many findings of importance. Notably, $52.7 \%$ of participants had a poor or negative drug attitude as assessed by the DAI-10, predicting poor adherence (non-adherence) to medication. This is in keeping with the existing literature that states that approximately $50 \%$ of patients with schizophrenia show non-adherence in the course of treatment $[16,17]$. Existing literature from similar Nepalese study populations have similar findings, one study from Poudel et al. found $37.3 \%$ of patients missed to take their medication and nearly two thirds of them sometimes missed their medication [18]. A study from Chaudhari et al. in an Indian study population found $52 \%$ of patients to be non-adherers [4].

Adherence to medication is affected by many factors, in Nepalese study populations it is recognised that availability and affordability of healthcare, alongside culture and beliefs of the patients can greatly affect compliance to medication $[9,10]$. This study found no significant variance in adherence between demographic groups, irrelevant of employment status, education or living arrangements. This contradicts existing literature that illiteracy and poor education are associated with poor medication adherence in schizophrenia $[19,20]$. Furthermore, in a study from Ghimire et al.,, unaffordability was cited as contributing factor for $68 \%$ of non-compliant patients with schizophrenia [10].

This study found that $52.6 \%$ of participants had only a basic education, reflecting findings published in 2013 , that only $60.3 \%$ of Nepalese people ages 15 and above can, with understanding, both read and write a short, simple sentences [21]. It was found that $57.9 \%$ of participants were unemployed; previous studies on similar cohorts have found unemployment rates as high as $86.7 \%$ [22]. A study from Liu et al. explores the hypothesis that illiterate people frequently experience social exclusion and this social adversity may increase risk of schizophrenia, it was found that illiterate participants were 2.08 times more likely to develop schizophrenia than the literate participants with no school education [23]. This is in keeping with the social defeat hypothesis which suggests long-term exposure to social defeat leads to sensitisation of mesolimbic dopamine system, thus increasing the risk of schizophrenia [24]. It is well recognised that rates of schizophrenia are higher amoungst the unemployed and uneducated $[25,26]$. Alongside the social defeat hypothesis, it is important to consider how negative symptoms and stigma may affect the equal opportunity of employment and education for this patient population. The majority of Nepalese people continue to believe schizophrenia is caused by bad fortune, some believing it is the result of previous sins, evil spirits, witchcraft and black magic; this negative stigma attached to schizophrenia within Nepalese culture is recognised to leave this patient group feeling rejected from society and increase difficulty in gaining education and employment [27, 28, 29]. Furthermore, it is understood that cognitive dysfunction and negative symptoms associated with schizophrenia are significantly associated with unemployment [30].

Approximately $30-50 \%$ of patients with schizophrenia have lack of insight into their condition, however the nature of insight is poorly defined across psychiatric literature [31, 32]. Insight is multidimensional and is related to awareness of illness, awareness of symptoms and understanding of need for treatment [11]. $36.8 \%$ of participants in this study population had poor insight, awareness of symptoms receiving the lowest score out of the three subscales closely followed by awareness of illness, with $84.2 \%$ of 
participants demonstrating poor awareness of symptoms and $78.9 \%$ demonstrating poor awareness of illness. It is understood that awareness of symptoms and illness is often greatly affected in schizophrenia as patients have a reduced capacity for self-reflectivity and self-awareness [33, 34].

Adherence is a significant problem in all patient populations in Nepal; a study from Bhandari et al. found adherence to antihypertensives at 56.5\% [35]. Unaffordability and difficulty travelling to the nearest hospital are commonly associated with non-adherence, this is equally true from the treatment of schizophrenia to tuberculosis [36]. However, in comparison to other chronic illnesses, schizophrenia can reduce one's ability to understand the importance of taking medication and the relationship between taking medication and reduced symptom burden. Insight is recognised to strongly correlate with adherence, with delusional patients often being the poorest adherers [37]. This study substantiates this hypothesis, analysis found that insight positively correlated with adherence, also finding that awareness of need for treatment correlated with adherence. Although there is a clear association between insight and adherence, it would be an assumption to say that lack of insight is causative of non-adherence in these patients, as there are many other factors that could be contributing to the outcome of nonadherence $[9,10,31]$.

Although this hypothesis has been demonstrated previously, there is a significant lack of research in the Nepalese patient population; a PubMed search of "schizophrenia Nepal" brings only 31 results. This study evidences that insight and adherence are correlated, despite significant familial, socio-cultural and environmental factors impacting on adherence in this study population. The study design was robust as the Birchwood Insight Scale (BIS) and Drug Attitude Inventory (DAI-10) are well recognised and validated scales for measuring insight and adherence, respectively $[11,12,12,14]$. The questionnaire was translated excellently; the simplicity of the questionnaire ensured easy completion for the patients with $100 \%$ data collection.

Limitations to this study included small sample size $(n=19)$, which reduces the external validity of the study. The patient population examined in this study may not be representative of all patients with schizophrenia across the Nepal, as Manipal Teaching Hospital is a private hospital based in a major city, Pokhara. Lack of accessibility for the rural Nepalese people may have limited their presentation to this outpatient department, and it is these rural Nepalese people that have the highest illiteracy rates and poorest living conditions, factors known to be associated with adherence [19, 20,38]. Upon reflection with a better understanding of the Nepalese population, the demographics section of the questionnaire should have measured illiteracy rates. Some literature suggests that up to $68 \%$ of patients with schizophrenia in Nepal consult a faith healer, further enquiries into the use of a faith healer would have enabled a deeper understanding of how this variable affected adherence [39]. Questions could have been added to the questionnaire on complexity of drug regime, side effects, duration of illness and drug and alcohol misuse, as these factors are all recognised to affect adherence [40,41, 42].

\section{Conclusions}


In conclusion, this cross-sectional, non-interventional study of patients with schizophrenia in Western Nepal found prevalent non-adherence to medication and evidenced that insight correlates with adherence in a population where this had not been evidenced previously. Although study findings did not suggest that patient demographics were associated with non-adherence, it is important to consider the possibility that these high rates of non-adherence have other contributing factors. The subjective experience of implementing this study, has clearly highlighted the lack of funding within the Nepalese healthcare system, especially within psychiatry. Less than $3 \%$ of the national budget is allocated to the health sector, of which $1 \%$ of the health budget is spent on mental health, furthermore there is no mental health act and the National Mental Health Policy formulated in 1997 is yet to be fully operational [43, 44]. Although most Nepalese people continue to hold negative beliefs about psychiatric conditions, such as schizophrenia, there is now an emerging body of literature from Nepal discussing the felt-stigma for psychiatric patients and the merit of anti-stigma campaigns moving forward [27, 29]. Although lack of insight may limit a patient's ability to make the decision to adhere to treatment; overcoming rural health inequality, cultural beliefs regarding psychiatric illness and unaffordability remain the great challenges.

\section{Abbreviations}

BIS-Birchwood Insight Scale

DAI-10Drug Attitude Inventory (10 question scale)

DAI-30 - Drug Attitude Inventory (30 question scale)

\section{Declarations}

Ethics approval and consent to participate: Ethical approval was obtained from the Institutional Ethical Review Committee of Manipal College of Medical Sciences, Pokhara, Nepal. An informed written consent was obtained from all participants capable of ethical consent. Some participants were not capable of providing ethical consent for their participation, in these circumstances a legal guardian or representative provided consent to participate on their behalf.

Availability of data and materials: The datasets used and analysed during the current study are available from the corresponding author on reasonable request.

Competing interests: The authors declare that they have no competing interests.

Funding: No source of funding was provided for this research project. Printing costs were covered by the Psychiatry Department at Manipal Teaching Hospital.

Authors: IS was involved in data collection between $10^{\text {th }}$ May 2019 and Friday $31^{\text {st }}$ May; conducted all data interpretation and wrote the manuscript. UL (First Year Resident Psychiatrist at Manipal Teaching Hospital) was involved in data collection between $10^{\text {th }}$ May 2019 and $10^{\text {th }}$ June 2019; provided 
translation during consultations for IS and reviewed the manuscript. JHK (Head of Psychiatry Department at Manipal Teaching Hospital) was supervisor for the project providing guidance, support and enabling ethical approval of the study. All authors read and approved the manuscript.

Consent for publication: Written consent to publish this information was obtained from the Institutional Ethical Review Committee of Manipal College of Medical Sciences, Pokhara, Nepal. A full waiver of the article processing charge was approved by Springer Nature waivers team.

Acknowledgements: Thank you to the staff of Manipal Teaching Hospital Library for translating the questionnaire.

\section{References}

1. Simeone JC, Ward AJ, Rotella P, Collins J, Windisch R. An evaluation of variation in published estimates of schizophrenia prevalence from 1990-2013: a systematic literature review. BMC psychiatry. 2015;15(1):193.

2. Psychosis and schizophrenia: management, Guidance and guidelines, National Institute of Clinical Excellence. www.nice.org.uk/guidance/cg82. Accessed 3 January 2019.

3. Burkhart PV, Sabaté E. Adherence to long-term therapies: evidence for action. Journal of nursing scholarship: an official publication of Sigma Theta Tau International Honor Society of Nursing. 2003;35(3):207-207.

4. Chaudhari B, Saldanha D, Kadiani A, Shahani R. Evaluation of treatment adherence in outpatients with schizophrenia. Ind Psychiatry J. 2017;26(2):215-22.

5. Lee $\mathrm{Y}$, Lee M-S, Jeong H-G, Youn H-C, Kim S. Medication adherence using electronic monitoring in severe psychiatric illness: 4 and 24 weeks after discharge. Clinical Psychopharmacology and Neuroscience. 2019;17(2):288.

6. Bitter I, Fehér L, Tényi T, Czobor P. Treatment adherence and insight in schizophrenia. Psychiatr Hung. 2015;30(1):18-26.

7. Tessier A, Boyer L, Husky M, Baylé F, Llorca P-M, Misdrahi D. Medication adherence in schizophrenia: The role of insight, therapeutic alliance and perceived trauma associated with psychiatric care. Psychiatry Res. 2017;257:315-21.

8. Bitter I, Fehér L, Tényi T, Czobor P. Treatment adherence and insight in schizophrenia. Psychiatria Hungarica: A Magyar Pszichiatriai Tarsasag tudomanyos folyoirata. 2015;30(1):18-26.

9. Dhungana M, Ghimire SR, Thapa M. Non-Compliance In Schizophrenia From Socio-Cultural, Familial And Environmental Perspective. Journal of Psychiatrists' Association of Nepal. 2017;6(2):22-7.

10. Ghimire SR. Poor medication compliance in schizophrenia from an illness and treatment perspective. EC Psychology and Psychiatry. 2017;3(4):131-41.

11. Birchwood M, Smith J, Drury V, Healy J, Macmillan F, Slade M. A self-report Insight Scale for psychosis: reliability, validity and sensitivity to change. Acta Psychiatrica Scandinavica. 
1994;89(1):62-67.

12. Hogan TP, Awad AG, Eastwood R. A self-report scale predictive of drug compliance in schizophrenics: reliability and discriminative validity. Psychological medicine. 1983;13(1):177-83.

13. Awad AG. Subjective response to neuroleptics in schizophrenia. Schizophrenia bulletin. 1993;19(3):609-18.

14. Nielsen RE, Lindström E, Nielsen J, Levander S. DAl-10 is as good as DAl-30 in schizophrenia. European Neuropsychopharmacology. 2012;22(10):747-50.

15. Nepal Health Research Council (NHRC). National Ethical Guidelines for Health Research in Nepal and Standard Operating Procedures. Kathmandu: NHRC. 2011.

16. Lacro JP, Dunn LB, Dolder CR, Leckband SG, Jeste DV. Prevalence of and risk factors for medication nonadherence in patients with schizophrenia: a comprehensive review of recent literature. The Journal of clinical psychiatry. 2002; 63(10):892-909.

17. Gray R, Wykes T, Gournay K. From compliance to concordance: a review of the literature on interventions to enhance compliance with antipsychotic medication. J Psychiatr Ment Health Nurs. 2002 Jun;9(3):277-84.

18. Poudel RS, Shrestha S, Prajapati A, Piryani RM. Factors affecting the medication taking behaviour of psychiatric patients: a preliminary study from central Nepal. Journal of Chitwan Medical College. 2017;7(4):44-50.

19. Eticha T, Teklu A, Ali D, Solomon G, Alemayehu A. Factors Associated with Medication Adherence among Patients with Schizophrenia in Mekelle, Northern Ethiopia. PLOS ONE. 2015 Mar 27;10(3):e0120560.

20. Hazarika S, Roy D, Talukdar SK. A study of medication nonadherence in schizophrenia. Dysphrenia. 2013;4(2):123-126.

21. Thapa SB. Relationship between education and poverty in Nepal. Economic Journal of Development Issues. 2013;148-161.

22. Banerjee I, Roy B, Sathian B, Banerjee I, Chakraborty PK, Saha A. Socio demographic profile and utilization pattern of antipsychotic drugs among schizophrenic inpatients: a cross sectional study from western region of Nepal. BMC psychiatry. 2013;13(1):96.

23. Liu T, Song X, Chen G, Buka SL, Zhang L, Pang L, et al. Illiteracy and schizophrenia in China: a population-based survey. Social psychiatry and psychiatric epidemiology. 2013;48(3):455-64.

24. Selten J-P, van der Ven E, Rutten BPF, Cantor-Graae E. The Social Defeat Hypothesis of Schizophrenia: An Update. Schizophr Bull. 2013;39(6):1180-6.

25. Padmavathi R, Rajkumar S, Kumar N, Manoharan A, Kamath S. PREVALENCE OF SCHIZOPHRENIA IN AN URBAN COMMUNITY IN MADRAS. Indian J Psychiatry. 1988;30(3):233-9.

26. Perkins $R$, Rinaldi $M$. Unemployment rates among patients with long-term mental health problems: $A$ decade of rising unemployment. Psychiatric Bulletin. 2002;26(8):295-8. 
27. Shyangwa PM. Knowledge and attitudes about mental illness among nursing staff. Journal of the Nepalese Medical Association. 2003; 42:27-31.

28. Acharya AK. Knowledge, attitude and practice of mental illness in a village population. Thesis submitted to the Department of Sociology and Anthropology, Tribhuvan University, Kathmandu, Nepal. 1998.

29. Adhikari SR, Pradhan SN, Sharma SC. Experiencing stigma: Nepalese perspectives. Kathmandu University Medical Journal. 2008;6(4):458-65.

30. McGurk SR, Meltzer HY. The role of cognition in vocational functioning in schizophrenia. Schizophrenia Research. 2000;45(3):175-84.

31. Baier M. Insight in Schizophrenia: A Review. Curr Psychiatry Rep. 2010;12(4):356-61.

32. Drake RJ, Lewis SW. Insight and neurocognition in schizophrenia. Schizophrenia Research. 2003;62(1-2):165-73.

33. Lysaker PH, Dimaggio G, Buck KD, Callaway SS, Salvatore G, Carcione A, et al. Poor insight in schizophrenia: links between different forms of metacognition with awareness of symptoms, treatment need, and consequences of illness. Comprehensive Psychiatry. 2011;52(3):253-60.

34. Amador XF, Strauss DH, Yale SA, Gorman JM. Awareness of Illness in Schizophrenia. Schizophr Bull. 1991;17(1):113-32.

35. Bhandari B, Bhattarai M, Bhandari M, Ghimire A, Pokharel PK, Morisky DE. Adherence to antihypertensive medications: population based follow up in Eastern Nepal. Journal of Nepal Health Research Council. 2015;13(29):38-42.

36. Mishra P, Hansen EH, Sabroe S, Kafle KK. Socio-economic status and adherence to tuberculosis treatment: a case-control study in a district of Nepal. The International Journal of Tuberculosis and Lung Disease. 2005;9(10):1134-9.

37. Van Putten T. Why do schizophrenic patients refuse to take their drugs? Arch Gen Psychiatry. 1974;31(1):67-72.

38. Singh S. Impact of long-term political conflict on population health in Nepal. Cmaj. 2004;171(12):1499-501.

39. Sapkota N, Shakya DR, Adhikari BR, Pandey AK, Shyangwa PM. Magico-religious Beliefs in Schizophrenia: A study from Eastern part of Nepal. Journal of College of Medical Sciences-Nepal. 2016;12(4):150-9.

40. Awad GA. Antipsychotic medications: Compliance and attitudes toward treatment. Current Opinion in Psychiatry. 2004;17(2):75-80.

41. Lang K., et al. "Medication adherence and hospitalization among patients with schizophrenia treated with antipsychotics". Psychiatric Services. 2010; 61(12);1239-1247.

42. Barkhof E, Meijer CJ, de Sonneville LMJ, Linszen DH, de Haan L. Interventions to improve adherence to antipsychotic medication in patients with schizophrenia-A review of the past decade. European Psychiatry. 2012;27(1):9-18. 
43. Regmi SK, Pokharel A, Ojha SP, Pradhan SN, Chapagain G. Nepal mental health country profile. International Review of Psychiatry. 2004;16(1-2):142-9.

44. Luitel NP, Jordans MJ, Adhikari A, Upadhaya N, Hanlon C, Lund C, et al. Mental health care in Nepal: current situation and challenges for development of a district mental health care plan. Conflict and health. 2015;9(1):3.

\section{Tables}

Table 1 - Demographics of study sample $(n=19)$ 


\begin{tabular}{|l|l|}
\hline Demographics & Study Population (n=19) \\
\hline Gender & \\
\hline N Total & 19 \\
\hline Male & $10(52.6 \%)$ \\
\hline Female & $9(47.4 \%)$ \\
\hline Age Category & \\
\hline N Total & 19 \\
\hline $18-20$ & $3(15.8 \%)$ \\
\hline $21-30$ & $10(52.6 \%)$ \\
\hline $31-40$ & $2(10.5 \%)$ \\
\hline 41-50 & $3(15.8 \%)$ \\
\hline $51-60$ & $1(5.3 \%)$ \\
\hline+60 & $0(0.0 \%)$ \\
\hline Ethnicity & \\
\hline N Total & 19 \\
\hline Chhetri & $5(26.3 \%)$ \\
\hline Bahun & $6(31.6 \%)$ \\
\hline Magar & $2(10.5 \%)$ \\
\hline Tamang & $3(15.8 \%)$ \\
\hline Other & $3(15.8 \%)$ \\
\hline Religion & \\
\hline N total & 19 \\
\hline Hindu & $12(63.2 \%)$ \\
\hline Buddhist & $7(36.8 \%)$ \\
\hline Other & $0(0.0 \%)$ \\
\hline Employment Status & \\
\hline N Total & 19 \\
\hline Full Time Employment & $2(10.5 \%)$ \\
\hline Casual Employment & $1(5.3 \%)$ \\
\hline Student & $4(21.1 \%)$ \\
\hline Carer of a dependent & $1(5.3 \%)$ \\
\hline Unemployed & $11(57.9 \%)$ \\
\hline Living Arrangements & \\
\hline N Total & 19 \\
\hline Living with parents & $12(63.2 \%)$ \\
\hline Home owner & $6(31.6 \%)$ \\
\hline Renting & $0(0.0 \%)$ \\
\hline Other & $1(5.3 \%)$ \\
\hline Education & \\
\hline N Total & 19 \\
\hline Basic Education & $10(52.6 \%)$ \\
\hline Higher Secondary Education & $9(47.4 \%)$ \\
\hline University & $0(0.0 \%)$ \\
\hline & \\
\hline
\end{tabular}

Table 2 - Break down of insight and adherence across the study population ( $\mathrm{n}=19)$ * 


\begin{tabular}{|l|l|}
\hline Scale & Study Population (n=19) \\
\hline BIS Total & \\
\hline N Total & 19 \\
\hline Mean Score & $8.79(3.95)$ \\
\hline Full Insight & $7(36.8 \%)$ \\
\hline Good Insight & $5(26.3 \%)$ \\
\hline Poor Insight & $7(36.8 \%)$ \\
\hline No Insight & $0(0.0 \%)$ \\
\hline Awareness of Symptoms & \\
\hline N Total & 19 \\
\hline Mean Score & $2.32(0.75)$ \\
\hline Good Insight & $3(15.7 \%)$ \\
\hline Poor Insight & $16(84.2 \%)$ \\
\hline Awareness of Illness & \\
\hline N Total & 19 \\
\hline Mean Score & $1.63(1.46)$ \\
\hline Good Insight & $4(21.1 \%)$ \\
\hline Poor Insight & $15(78.9 \%)$ \\
\hline Awareness of Need for Treatment & \\
\hline N Total & 19 \\
\hline Mean Score & $2.42(1.74)$ \\
\hline Good Insight & $12(63.2 \%)$ \\
\hline Poor Insight & $7(36.8 \%)$ \\
\hline Drug Attitude Inventory (DAI-10) & \\
\hline N Total & 19 \\
\hline Mean Score & $1.05(3.85)$ \\
\hline Positive Score & $9(47.4 \%)$ \\
\hline Negative Score & $6(31.6 \%)$ \\
\hline Score = 0 & $4(21.1 \%)$ \\
\hline & \\
\hline
\end{tabular}

*Break down of insight (according to the Birchwood Insight Scale and subscales) and adherence (according to the Drug Attitude Inventory) across the study population $(\mathrm{n}=19)$

Table 3 - Analysis of variance of DAI-10 scores according to participant demographics 


\begin{tabular}{|c|c|c|c|c|}
\hline Demographics & $\mathbf{N}$ & Mean DAI-10 Score & $95 \% \mathrm{CI}$ & P Value* \\
\hline Gender & & & & 0.866 \\
\hline N Total & 19 & $1.05(3.85)$ & $-0.80,2.91$ & \\
\hline Male & 10 & $1.20(3.55)$ & $-2.47,4.25$ & \\
\hline Female & 9 & $0.89(4.37)$ & $-0.80,2.91$ & \\
\hline Age Category & & & & 0.056 \\
\hline N Total & 19 & $1.05(3.85)$ & $-0.80,2.91$ & \\
\hline $18-20$ & 3 & $-2.67(3.06)$ & $-10.26,4.92$ & \\
\hline $21-30$ & 10 & $1.40(3.13)$ & $-0.84,3.64$ & \\
\hline $31-40$ & 2 & $7.00(1.41)$ & $-5.71,19.71$ & \\
\hline $41-50$ & 3 & $0.67(4.16)$ & $-9.68,11.01$ & \\
\hline $51-60$ & 1 & -2.00 & & \\
\hline Ethnicity & & & & 0.301 \\
\hline N Total & 19 & $1.05(3.85)$ & $-0.80,2.91$ & \\
\hline Chhetri & 5 & $-2.00(2.45)$ & $-5.05,1.04$ & \\
\hline Bahun & 6 & $2.33(4.08)$ & $-1.95,6.62$ & \\
\hline Magar & 2 & $2.00(5.66)$ & $-48.82,52.82$ & \\
\hline Tamang & 3 & $0.67(4.16)$ & $-9.68,11.01$ & \\
\hline Other & 3 & $3.33(3.06)$ & $-4.26,10.92$ & \\
\hline Religion & & & & 0.755 \\
\hline $\mathrm{N}$ total & 19 & $1.05(3.85)$ & $-0.80,2.91$ & \\
\hline Hindu & 12 & $0.83(4.13)$ & $-1.79,3.46$ & \\
\hline Buddhist & 7 & $1.43(3.60)$ & $-1.90,4.76$ & \\
\hline Employment Status & & & & 0.281 \\
\hline N Total & 19 & $1.05(3.85)$ & $-0.80,2.91$ & \\
\hline Full Time Employment & 2 & $2.00(2.83)$ & $-23.41,27.41$ & \\
\hline Casual Employment & 1 & -2.00 & & \\
\hline Student & 4 & $-1.00(4.76)$ & $-8.58,6.58$ & \\
\hline Carer of a dependent & 1 & 8.00 & & \\
\hline Unemployed & 11 & $1.27(3.38)$ & $-1.00,3.54$ & \\
\hline Living Arrangements & & & & 0.208 \\
\hline N Total & 19 & $1.05(3.85)$ & $-0.80,2.91$ & \\
\hline Living with parents & 12 & $0.00(3.19)$ & $-2.03,2.03$ & \\
\hline Home owner & 6 & $2.33(4.63)$ & $-2.53,7.20$ & \\
\hline Other & 1 & 6.00 & & \\
\hline Education & & & & 0.388 \\
\hline N Total & 19 & $1.05(3.85)$ & $-0.80,2.91$ & \\
\hline Basic Education & 10 & $1.80(4.66)$ & $-1.53,5.13$ & \\
\hline Higher Secondary Education & 9 & $0.22(2.73)$ & $-1.88,2.32$ & \\
\hline
\end{tabular}

*Means of demographic groups compared using one-way ANOVA analysis (0.05 significance level)

Table 4 - Correlation between Birchwood Insight Scale (BIS) and subscales and the Drug Attitude Inventory (DAI-10) 


\begin{tabular}{|l|l|l|l|}
\hline Insight Scale & N & Pearson Correlation Coefficient & P Value* \\
\hline BIS Total & 19 & 0.585 & 0.009 \\
\hline Awareness of Symptoms & 19 & 0.032 & 0.895 \\
\hline Awareness of Illness & 19 & 0.112 & 0.647 \\
\hline Awareness of Need for Treatment & 19 & 0.609 & 0.006 \\
\hline
\end{tabular}

*Correlation was tested using Pearson's 2-tailed analysis at 0.01 significance level

\section{Supplementary Files}

This is a list of supplementary files associated with this preprint. Click to download.

- STROBEChecklist.doc 